\title{
Tailored design of NKT-stimulatory glycolipids for polarization of immune responses
}

\author{
Jung-Tung Hung ${ }^{1}$, Jing-Rong Huang ${ }^{1}$ and Alice L. Yu ${ }^{1,2^{*}}$
}

\begin{abstract}
Natural killer T (NKT) cell is a distinct population of T lymphocytes that can rapidly release massive amount of Th1 and Th2 cytokines upon the engagement of their T cell receptor with glycolipids presented by CD1d. The secreted cytokines can promote cell-mediated immunity to kill tumor cells and intracellular pathogens, or suppress autoreactive immune cells in autoimmune diseases. Thus, NKT cell is an attractive target for developing new therapeutics to manipulate immune system. The best-known glycolipid to activate NKT cells is a-galactosylceramide (a-GalCer), which has been used as a prototype for designing new NKT stimulatory glycolipids. Many analogues have been generated by modification of the galactosyl moiety, the acyl chain or the phytosphingosine chain of a-GalCer. Some of the analogues showed greater abilities than a-GalCer in polarizing immune responses toward Th1 or Th2 dominance. Among them, several analogues containing phenyl groups in the lipid tails were more potent in inducing Th1-skewed cytokines and exhibited greater anticancer efficacy than a-GalCer. Analyses of the correlation between structure and activity of various a-GalCer analogues on the activation of iNKT cell revealed that CD1d-glycolipid complexes interacted with the same population of iNKT cell expressing similar T-cell receptor V $\beta$ as a-GalCer. On the other hand, those phenyl glycolipids with propensity for Th1 dominant responses showed greater binding avidity and stability than a-GalCer for iNKT T-cell receptor when complexed with CD1d. Thus, it is the avidity and stability of the ternary complexes of CD1d-glycolipid-iNKT TCR that dictate the polarity and potency of immune responses. These findings provide a key to the rationale design of immune modulating glycolipids with desirable Th1/Th2 polarity for clinical application. In addition, elucidation of a-GalCer-induced anergy, liver damage and accumulation of myeloid derived suppressor cells has offered explanation for its lacklustre anti-cancer activities in clinical trials. On other hand, the lack of such drawbacks in glycolipid analogues containing phenyl groups in the lipid tails of a-GalCer coupled with the greater binding avidity and stability of CD1d-glycolipid complex for iNKT T-cell receptor, account for their superior anti-cancer efficacy in tumor bearing mice. Further clinical development of these phenyl glycolipids is warranted.
\end{abstract}

Keywords: iNKT cell, a-galactosylceramide, Anergy, Myeloid-derived suppressive cell

\section{Background}

Natural killer T (NKT) cells play a central role in connecting innate immunity and adaptive immunity. They can modulate immune responses by orchestrating other immune cells, including $\mathrm{T}$ cells, B cells, natural killer (NK) cells and dendritic cells (DCs) [1]. There are two major subpopulations of NKT cells, classical (or type I)

\footnotetext{
* Correspondence: a1yu@ucsd.edu

${ }^{1}$ Institute of Stem Cell \& Translational Cancer Research, Chang Gung

Memorial Hospital at Linkou and Chang Gung University, No. 5, Fu-Shin St., Kuei Shang, Taoyuan 333, Taiwan

${ }^{2}$ Department of Pediatrics, University of California in San Diego, San Diego, CA, USA
}

NKT cells and non-classical (or type II) NKT cells [2-4]. Those two subpopulations of NKT cells are response to lipid antigens in a CD1d-dependent manner. Many glycolipid antigens for NKT cells have been identified, including bacterial glycolipids such as $\alpha$-galacturonosyl ceramide, $\alpha$ glucuronosyl ceramide and $\alpha$-galactosyl diacylglycerol and mammalian glycolipids such as isoglobotrihexosylceramide (iGb3) and disialoganglioside GD3 [5-7]. In addition, $\alpha$ galactosylceramide ( $\alpha$-GalCer) isolated from marine sponge is found to have a potent activity to activate the classical NKT cells and display anticancer effects in tumor-bearing mouse model. The robust immune stimulating activities of 
$\alpha$-GalCer inspire researchers to use the $\alpha$-GalCer as template to design more potent immune modulating glycolipids. For example, glycolipid $\mathrm{OCH}$ prevents the experimental autoimmune encephalomyelitis [8], $\alpha-\mathrm{C}$ Gal protects mice against malaria and melanoma metastases [9] and phenyl-glycolipids suppress tumor growth in mouse models as well as strong adjuvant effect on DNA vaccine $[10,11]$. The differential biological activities of various $\alpha$-GalCer analogues provide valuable insights into the relationship between structural modification of $\alpha$-GalCer and the immune-modulating activities and thereby facilitating the design of novel analogues with desirable properties for various clinical applications.

\section{Subsets and functions of NKT cells}

NKT cells are a unique subset of $\mathrm{T}$ lymphocytes that coexpress $\alpha / \beta$ T cell receptor (TCR) and NK lineage markers, i.e. NK1.1, CD122 (IL-2R $\beta$ ) and various Ly49 molecules. Based on the phenotype and content of cytokines, NKT cells have been divided into two main subsets: type I NKT cells, known as invariant NKT (iNKT) cells producing IFN- $\gamma$, IL-2, IL-4, IL-5 and IL-13, and type II NKT cells which encompass many diverse NKT cells secreting IFN- $\gamma$, TNF- $\alpha$, IL-17A and IL-6 [12]. The iNKT cells can be found in thymus, liver, bone marrow, spleen and peripheral blood. In mice, iNKT cells comprise of approximately 1 to $3 \%$ of lymphocytes in the circulation and are enriched in the liver where iNKT can constitute up to $30 \%$ of resident lymphocytes. These cells are CD1drestricted $\mathrm{CD} 4^{+}$or $\mathrm{CD} 4^{-} \mathrm{CD} 8^{-} \mathrm{T}$ cells with NK markers and exhibit an activated phenotype $\left(\mathrm{CD} 44^{\text {high }} \mathrm{Ly} 6 \mathrm{C}^{\text {high }} \mathrm{IL}\right.$ $\left.2 \mathrm{R} \beta^{\text {high }}\right)$. The TCR usage of iNKT cells is quite unique with a semi-invariant $\alpha$-chain consisting of V $\alpha 14 \mathrm{~J} \alpha 18$, and preferential usages of $\mathrm{V} \beta 2, \mathrm{~V} \beta 7$ or $\mathrm{V} \beta 8.2$ for $\beta$-chain in mice [13-18]. In human, a similar population of cells expressing V $\alpha 24 \mathrm{~J} \alpha 18$ and $\mathrm{V} \beta 11$ has been identified $[19,20]$. Although the type II NKT cells are also responsive to CD1d-presented glycolipids, which do not include $\alpha$ GalCer [21], they express polyclonal TCR repertoires similar to the highly diverse TCRs of conventional CD4 and CD8 T cells.

Unlike conventional $\mathrm{T}$ cells, which recognize peptides presented by major histocompatibility complex (MHC) molecules, both iNKT or type II NKT cells recognize glycolipid antigens presented by CD1d proteins which are nonpolymorphic MHC class I-like molecules [22-24]. CD1d proteins are expressed on cells of hematopoietic origin such as dendritic cells, B cells, T cells and macrophages [25]. According to the crystal structure of CD1d protein, antigenbinding site of CD1d molecules is composed of two channels, A' and F' channels, which bind to an acyl chain and a phytosphingosine chain, respectively [26-31]. Antigens such as glycosylceramide and glycosylphosphatidylinositol could be presented by CD1d. Their alkyl chains are inserted into hydrophobic grooves A' and F' channels of CD1d so that their carbohydrate moieties protrude to contact with TCR of NKT cells [23, 32].

Upon engagement with CD1d/ $\alpha$-GalCer complex, iNKT cells become activated with rapid production of cytokines within minutes [33], such as interleukin-4 (IL-4) and interferon- $\gamma$ (IFN- $\gamma$ ), along with upregulation of activation markers such as CD69, augmented cell proliferation and increased cytotoxic capacity [23, 34-36]. The secreted cytokines will not only trigger activation of $\mathrm{T}$ cells, NK cells, B cells and dendritic cells but also direct immune responses toward Th1 or Th2 responses [37, 38]. For instance, IFN- $\gamma$ promotes Th1 cell differentiation and NK cell activation, which is essential for defense against tumors and various intracellular pathogens. Conversely, IL-4 controls the initiation of Th2 responses, which inhibit Th1-mediated autoimmune responses such as collageninduced arthritis (CIA), experimental autoimmune encephalomyelitis (EAE) and type I diabetes in NOD mice. Hence, iNKT cells are thought to play a central role in innate and adaptive immunity against viruses, bacteria, parasites, autoimmune diseases and cancer [23, 39-42].

Type II NKT cells do not respond to $\alpha$-GalCer and therefore they cannot be identified by $\alpha-G a l C e r / C D 1 d$ tetramers. Such technical limitations have hindered efforts to interrogate type II NKT cells and, consequently, relatively little is known about their roles in immune system. So far, a major subset of type II NKT cells has been found to respond to $\beta$-linked self-glycolipid sulfatide [43]. Comparing the crystal structures of type I NKT- $\alpha-G a l C e r /$ CD1d complex and type II NKT cell TCR-sulfatide/CD1d complex, Girardi et al. found that the type II NKT TCR bound to sulfatide/CD1d with an perpendicular orientation but the type I NKT TCR bound to $\alpha$-GalCer/CD1d with an diagonal orientation [44]. This study suggests that the immune-modulating effects of iNKT and type II NKT cells might be quite different. Indeed, it is known that type II NKT cells played an important role in anergy induction in the inflammatory liver [45], suppression of graft-versushost disease (GVHD) [46] and inhibition of airway asthma induced by Type I NKT cells in mouse model [47]. In addition, type II NKT cells might be involved in cancer progression by secreting IL-13 to inhibit tumor-specific $\mathrm{CD}^{+} \mathrm{T}$ cells [48]. In human, an increase in IL-13secreting type II NKT cells stimulated by lysophosphotidylcholine was observed in patients with multiple myeloma [49]. Moreover, tumor growth was significantly increased in J $\alpha 18^{-/-}$mice, which lack type I NKT cells but still retain type II NKT cells, compared to that in CD1d $\mathrm{d}^{-/-}$ mice, which lack both type I and type II NKT cells [50]. Similarly, Izhak et al. demonstrated that enhanced tumor growth in ${\mathrm{J} \alpha 18^{-/-}}^{-}$mice was not undermined by blocking regulatory $\mathrm{T}$ (Treg) cell blockade with anti-CD25 antibody 
alone, but was abrogated when both type II NKT cells and Tregs were blocked. Importantly, adoptive transfer of type I NKT cells can restore the protection against tumor in J $18^{-/-}$mice treated with anti-CD25 antibody [51]. These results indicate that type II NKT cells might suppress tumor immunity to promote tumor progression, and type I NKT cells might inhibit the immune suppressive ability of type II NKT cells.

\section{Avidity and stability of TCR-glycolipids-CD1d complex dictate the differential capacities of a-GalCer and its analogues for NKT activation}

$\alpha$-GalCer, also known as KRN7000, is a simplified glycolipid analogue of agelasphin, which was originally isolated from a marine sponge Agelas mauritianus [52, 53]. $\alpha$-GalCer is composed of an $\alpha$-linked galactose, a phytosphingosine and an acyl chain. Preclinical evidence of the antitumor activity of $\alpha$-GalCer has spurred research toward the identification of its mechanism of action [23, 54]. It is a well characterized antigen for CD1d-reactive iNKT cells in mouse and human [55-57]. X-ray crystallographic analysis of binary complex of $\alpha$-GalCer and CD1d molecule revealed that the long lipid chain of $\alpha$-GalCer is stabilized by hydrophobic interactions with amino acids from the $\beta$-sheet floor and helices of CD1d. Specifically, the A' and the F' channels of CD1d can accommodate an alkyl chain up to 26 and 18 carbon atoms long, respectively [26]. Furthermore, the length of lipids of $\alpha$-GalCer can modulate the affinity of iNKT cell TCR and the threshold of iNKT cell activation [58]. $\mathrm{OCH}$, an $\alpha-$ GalCer analogue with a shorter phytosphingosine chain, stimulates iNKT cells to secrete higher amounts of IL-4 than IFN- $\gamma$, triggering the immune response toward Th2 (Fig. 1). The possible molecular mechanisms of $\mathrm{OCH}-$ induced Th2 response might be related to its less avidity and stability in binding to CD1d than $\alpha$-GalCer, leading to a less sustained TCR stimulation on iNKT cells $[8,59,60]$. Other $\alpha$-GalCer analogues containing sulfonamide linkage to acyl chain induced Th2 response comparable to $\mathrm{OCH}$ in mouse splenocytes [61]. Besides, our group has shown that $\alpha$-GalCer analogues containing a phenyl group in their acyl tail are more effective than $\alpha$-GalCer in inducing Th1 cytokines/chemokines and human NKT cell expansion. Similar to $\alpha$-GalCer, phenyl glycolipids cannot induce cytokine production in CD1d knockout mouse, suggesting that presentation of phenyl glycolipids by CD1d protein is necessary to activate iNKT cells [60]. Moreover, one of the phenyl glycolipids, 7DW8-5 which has a shorter fatty acyl chain with a fluorinated benzene ring at the end, displayed adjuvant activity for malaria vaccine and enhanced $\mathrm{CD}^{+} \mathrm{T}$ cell response in non-human primate [62]. The differential cytokine response induced by phenyl glycolipids did not result from differential usage of TCR $\beta$ chain. In fact, the

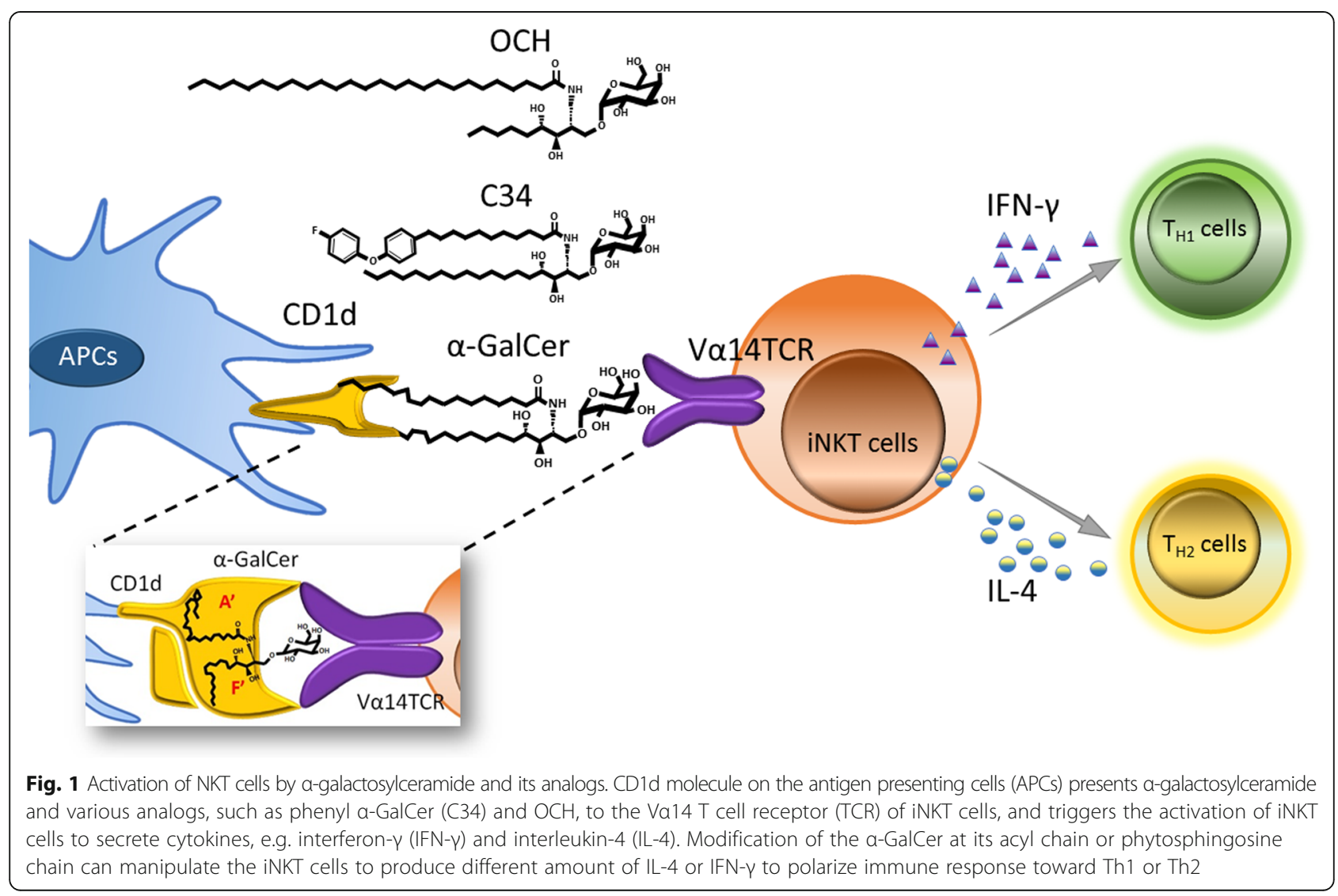


major $\beta$ chain used by iNKT cells for the recognition of phenyl glycolipids and $\alpha$-GalCer were V $\beta 8.1$ and V $\beta 8.2$ in mouse and V $\beta 11$ in human. On the other hand, phenyl glycolipids displayed greater binding strengths between CD1dglycolipid complex and iNKT cells than $\alpha$-GalCer. Additionally, the rate of dissociation of CD1d-phenyl glycolipid complex from iNKT TCR was significantly slower than that of CD1d- $\alpha$-GalCer complex. These results suggest that both the avidity and stability of the ternary complex of CD1d-glycolipid-iNKT TCR play a key role in dictating the induction of cytokines/chemokines. Notably, the binding strength of the ternary structure CD1d-glycolipid-iNKT TCR is much more relevant to iNKT cell activation than that of the binary structure CD1d-glycolipid, as reflected by the differential cytokine responses to glycolipids with identical lipid tails but different glycan head [63]. More importantly, unlike $\alpha$-GalCer, these phenyl glycolipids do not induce NKT cell anergy nor accumulation of myeloid-derived suppressor cells (MDSCs) [10, 11, 64], which will be elaborated in later section.

In addition, the orientation and position of hydroxyl group at the galactose ring of $\alpha$-GalCer are believed to be crucial for iNKT cell recognition [6]. The $2 ', 3$ ', and 4'-OH of the galactose moiety form hydrogen bonds with Gly96a, Phe29a and Ser30a, respectively, of the invariant TCR $\alpha$-chain. Upon removal of the $2^{\prime}-\mathrm{OH}$, the cytokine response declined. However, the $3^{\prime}-$ or $4{ }^{\prime}$-deoxy or -fluoro analogues of $\alpha$-GalCer remain active [65]. According to the crystal structure of ternary complex of NKT TCR/ $\alpha-$ GalCer/CD1d, the $6^{\prime}-\mathrm{OH}$ of the galactose moiety of $\alpha$-GalCer points toward solvent [6], and thus it might or might not influence the binding of iNKT TCR to $\alpha$-GalCer/CD1d complex. Indeed, addition of an extra Gal [66] or small fluorophores [67] at $6^{\prime}-\mathrm{OH}$ of the galactose moiety retains the activity to stimulate NKT cells. Conjugation with polyethylene glycol at 6'amide group of the galactose moiety activates murine iNKT cells more efficiently than $\alpha$-GalCer. When acting as an adjuvant for the $\beta$-galactosidase protein vaccine, the $\alpha$-GalCer analogue with pegylation, which increased the water solubility, at the $6^{\prime}$-amide of galactose moiety elicited high titers of antigen-specific antibodies in mouse, even though it induced lower production of IFN$\gamma$ than $\alpha$-GalCer [68]. In contrast, $\alpha$-GalCer analogue with a naphthylurea at $6^{\prime}$-amide of galactose moiety induced Th1 bias immune response and prevented lung metastasis of melanoma [69] whereas $\alpha$-GalCer analogue with a methyl group at $6^{\prime}-\mathrm{OH}$ of galactose moiety induced slightly higher production of IL-4 and IFN- $\gamma$ in mouse [70]. We also showed that Gal-6' - phenylacetamidesubstituted $\alpha$-GalCer analogues carrying p-nitro-, ptert-butyl, or $\mathrm{o}^{-}, \mathrm{m}-$, or $\mathrm{p}$-methyl groups elicited higher IFN- $\gamma /$ IL- 4 secretion ratios than $\alpha$-GalCer [71]. In contrast, we have recently shown that adding acyl chain at the $6^{\prime}-\mathrm{OH}$ of galactose moiety of $\alpha$-GalCer can stimulate iNKT cells to secrete more Th2-biased cytokines [72]. Interestingly, two $6^{\prime}-\mathrm{OH}$ analogues of $\alpha-$ GalCer, NU- $\alpha-$ GalCer and PyrC- $\alpha-$ GalCer, induced strong Th1-biased immune response leading to reduced lung metastasis in the B16 melanoma model [73]. These findings suggest that modifications at $6^{\prime}-\mathrm{OH}$ of galactose moiety may change the interaction between NKT TCR and $\alpha$ GalCer-CD1d complex, thereby modulating the cytokine secretion of iNKT cells in vitro and in vivo.

Based on the X-ray crystallography study, the $\mathrm{NH}$ group of the amide of $\alpha$-GalCer phytosphingosine chain forms hydrogen bond to Thr156 at the $\alpha 2$ loop of mouse CD1d [29], indicating that the $\mathrm{NH}$ group might play a role in the activity of $\alpha$-GalCer. Indeed, the $\mathrm{NH}$ group isomer, having the inverted $\mathrm{NH}$ stereochemistry, showed weaker activity for stimulating proliferation of mouse iNKT cells and no activity for human iNKT cells [74]. RCAI-18, $\alpha-$ GalCer analogue with azetidine ring, induced slightly lower levels of IFN- $\gamma$, IL-2, IL-4, IL-10 and IL-13 when compared with $\alpha$-GalCer. However, RCAI-8, a RCAI-18 analogue with replacement of the azetidine ring with pyrrolidine ring, did not stimulate murine iNKT cells to produce cytokines [75]. Furthermore, Shiozaki et al. showed that replacing the amide group of $\alpha$-GalCer with an ester reduced the secretion of IFN- $\gamma$ and IL-4 [76]. In our study, we found that substituting the hydrogen of amide group of $\alpha$ GalCer with methyl group lowered its capacity in inducing cytokine production of iNKT cell [72]. Besides, $\alpha$-GalCer analogue DB06-1, which contains the substitution of a carbonyl oxygen with a sulfur atom, can increase IFN- $\gamma$ and IL-2p70 production and activate NK cells in vivo [77]. In addition, $\alpha-C-G a l C e r, ~ a$ $\mathrm{C}$-glycoside of $\alpha$-GalCer, displayed a more potent antimalarial activity and antitumor activity in mice [9], but it did not effectively stimulate human iNKT cells in vitro [78]. Those data suggest that different modifications of phytosphingosine or acyl chain may affect the binding affinity of TCR with glycolipids-CD1d complex, and thereby modulating the magnitude and the Th1/Th2 polarity of responses of iNKT cells.

\section{Clinical trials of a-galactosylceramide}

In preclinical studies, the anti-cancer activity of $\alpha$ GalCer has been demonstrated in tumor-bearing mouse models. Prompted by these findings, Giaccone et al. conducted a phase I clinical trial of $\alpha$-GalCer in patients $(n=24)$ with advance cancer. The dose was escalated from 50 to $4800 \mu \mathrm{g} / \mathrm{m}^{2}$ at a schedule of intravenous injection on days 1,8 and 15 of a 4weekly cycle. Toxicities of $\alpha$-GalCer were minimal, including vomiting, malaise and chills in one patient and 
grade 3 fever and headache in another patient. All side effects occurred after the first administration only. Neither drug accumulation nor serum saturation of $\alpha$ GalCer was observed by pharmacokinetic analyses. Furthermore, no detectable trace of $\alpha$-GalCer was found in the urine at any dose level. Surprisingly, in patients with high number of NKT cells (>333 cells/ $\mathrm{mL}$ ), the number of circulating iNKT cells rapidly declined to undetectable levels within $24 \mathrm{~h}$ after the first injection of $\alpha$-GalCer. Even after two additional injections, circulating iNKT cells remained negligible or undetectable. Notably, patients with pretreatment iNKT cell numbers higher than median number in all patients had greater cytokine productions induced by $\alpha$-GalCer. Five of 10 patients in NKT-high group showed significant increases in serum levels of both GM-CSF and TNF- $\alpha$. In contrast, GM-CSF and TNF- $\alpha$ levels barely rose in the NKT-low group after $\alpha$ GalCer administration [79]. In addition, the impacts of age and cancer status were assessed to provide information for iNKT cell-based immunotherapy [80]. The percentages of circulating iNKT cell were significantly lower in patients with melanoma $(n=17)$ and breast cancer $(n=10)$ than in healthy donors $(n=40)$. The percentages of circulating iNKT cells were also lower in patients with colorectal cancer $(n=33)$, lung cancer $(n=8)$ and RCC $(n=10)$ than healthy controls but the difference did not reach statistical significance. In addition, in vitro expansion capability of iNKT cells from cancer patient in response to $\alpha$-GalCer was less than that from healthy donor. Moreover, the percentage and absolute number of circulating iNKT cells decreased with increasing age, although age did not affect the expansion capability of iNKT cells stimulated with $\alpha$-GalCer [80]. These results suggest that the cytokine production and iNKT cell expansion induced by $\alpha$-GalCer in patients depend on the pretreatment circulating iNKT cell population size which is influenced by type of cancer and patient age.

Several studies have shown that $\alpha$-GalCer-pulsed DC can inhibit tumor growth in mouse and expand human iNKT cells in vitro [81-83]. These findings prompted a few clinical trials to evaluate the antitumor efficacy of $\alpha$-GalCer-pulsed DC. In the phase I trial conducted by Nieda et al., patients $(n=12)$ received $5 \times 10^{6} \alpha$-GalCer-pulsed DC on day 0 and 14 . Increased serum level of IFN- $\gamma$ and number of NKT cells were observed initially but the number of NKT cells fell by day 2 after treatment. The majority of patients experienced temporary exacerbation of tumor symptoms, including enlargement of tumor, bone pain and biochemical abnormalities. However, a few patients showed tumor responses, such as decreased serum tumor markers $(n=2)$, increased necrosis in tumor $(n=1)$ and improvements in hepatocellular enzyme levels $(n=2)$ [84]. Chang et al. demonstrated that injection of unpulsed DC at week 0 and $\alpha$ GalCer-pulsed matured DC at week 4 and 8 led to a dramatic expansion of NKT cells in all patients $(n=$ 5) after the third injection [85]. In addition, Uchida et al. administered $\alpha$-GalCer-pulsed DC into the nasal submucosa of patients $(n=9)$ and found that the number of circulating NKT cells increased [86]. Kunii et al. treated 8 patients with recurrent head and neck squamous cell carcinoma by intra-arterial infusion of ex vivo expanded autologous iNKT cells in combination with nasal submucosal injection of $\alpha$ GalCer-pulsed DC. They found that both the number of circulating iNKT cells and IFN- $\gamma$-producing cells increased (7/8), However, mild to severe adverse events were observed i.e. a grade 3 pharyngocutaneous fistula $(n=1)$, low-grade fever $(n=4)$, headache $(n=1)$, and fatigue $(n=2)$. In spite of these adverse events, three partial responses, four stable diseases and one progressive disease were observed [87]. Furthermore, the administration routes of $\alpha$-GalCerpulsed DC were evaluated in patients with metastatic malignancy [88]. Increases in serum IFN- $\gamma$ levels in patients were seen after intravenously injection of 5 $\times 10^{6}$ of $\alpha$-GalCer-pulsed DC but were not observed in patients after intradermally injection of the same dose of $\alpha$-GalCer-pulsed DC. Notably, six patients had stable disease, which was defined as no substantial increase in tumor masses or tumor markers, during the study period of 3 months. Taken together, these reports suggest that $\alpha$-GalCer-pulsed DC might induce clinically beneficial immune responses in patients with cancer.

Moreover, the antiviral effects of $\alpha$-GalCer on hepatitis viruses were evaluated. A randomized placebo-controlled phased I/II trial of $\alpha$-GalCer in chronic hepatitis $C$ virus (HCV) infection was conducted by Veldt et al. A total of 40 patients were enrolled and three dosage levels of $\alpha$ GalCer $(0.1,1$ and $10 \mu \mathrm{g} / \mathrm{kg})$ were tested. $\alpha$-GalCer was well tolerated in patients with $\mathrm{HCV}$, with only mild adverse events including fatigue, myalgia, back pain, headache, rhinitis, fever, chills and dizziness. As shown in Giaccone's report [79], the number of circulating iNKT dropped immediately after the first injection of $\alpha$-GalCer in patients with $\mathrm{HCV}$, but recovered approximately 2 days later. Subsequent second and third injection of $\alpha$-GalCer did not further enhance the iNKT cell number. In several individuals, productions of IFN- $\gamma$ and TNF- $\alpha$ were observed. One patient showed a mark decrease in $\mathrm{HCV}$ RNA after the first injection of $\alpha-G a l C e r$, but no further reduction after the second and third injection. At the end of this trial, no significant changes in HCV RNA between the two groups were noted [89]. Another randomized placebo-controlled phased I/II trial of $\alpha$-GalCer in 27 
patients with chronic hepatitis B virus (HBV) was conducted by Woltman et al. [90], using the same doseschedule as Veldt's study [89]. The adverse events were mostly flu-like syndromes except that four patients, who received $\geq 1 \mu \mathrm{g} / \mathrm{Kg}$ of $\alpha$-GalCer, had fever and severe rigors lasting for $1 \mathrm{~h}$ to 2 days. This might result from relatively high iNKT cell levels in the blood of HBV patients, which had high stimulatory effects on the immune system. The number of circulating iNKT cells fluctuated, similar to the report by Veldt et al. A transient rise in serum TNF- $\alpha$ was observed only in patients with high pretreatment iNKT cell number. Four patients showed decrease in HBV DNA levels following the first injection of $\alpha$-GalCer, but only one sustained decrease in HBV DNA levels after the second and third injection of $\alpha$-GalCer. In general, the HBV DNA changes in patients injected with $\alpha$-GalCer was not statistically significantly different from those in placebo group [90].

Overall, the antitumor and antiviral efficacies of $\alpha$ GalCer in human are deemed too meagre to warrant further clinical trials. On the other hand, the route of injection, dose and schedule might have influenced the therapeutic efficacy of $\alpha$-GalCer. Although $\alpha$-GalCer did not show robust clinical efficacy in these early phase clinical trials, the use of more potent Th1- biased $\alpha$-GalCer analogues containing phenyl group in lipid tail might improve the anti-tumor efficacy in human in the future.

\section{Possible mechanisms for the limited clinical activities of $\mathbf{a}$-GalCer}

The lacklustre clinical efficacy of $\alpha$-GalCer in cancer and hepatitis may be attributable to $\alpha-G a l C e r$ induced liver toxicity [91], NKT cells anergy [92] and myeloid-derived suppressor cells (MDSCs) accumulation [64]. These features might have undermined the clinical efficacy of $\alpha$-GalCer.

One day after injection of $\alpha$-GalCer in mice, several white spots $(0.5-1 \mathrm{~mm}$ in diameter) were readily discernible on the surface of liver, which consisted of hepatocyte damage accompanied by lymphocyte infiltration in liver parenchyma and a rise in serum levels of SGOT and SGPT. Such hepatocyte damage induced by $\alpha$-GalCer was dependent on NK/NKT cells [91]. Furthermore, we demonstrated that $\alpha-G a l C e r$ significantly upregulated the expression of TRAIL and FasL in liver iNKT cells, leading to injury of liver cells which constitutively express Fas and death receptor 5 (DR5) (Fig. 2). In comparison, negligible or only a very slight increase of the TRAIL and FasL on liver iNKT cells was detected in mice injected with the $\alpha$-GalCer

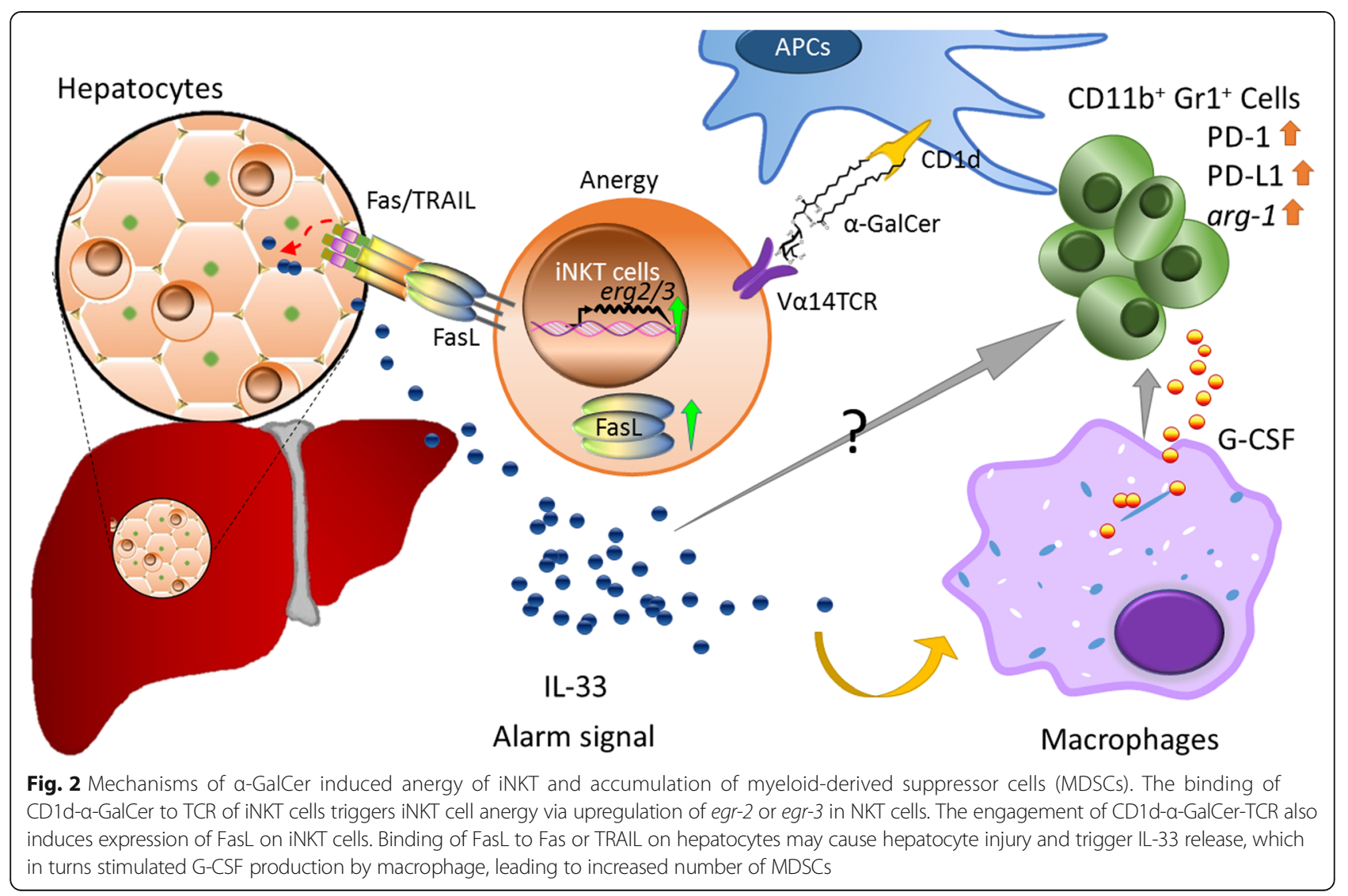


analogues containing phenyl group at the acyl chain [64]. Indeed, no white spots on liver were observed in mice injected with these phenyl analogues, suggesting that these phenyl glycolipids may have the advantage of little or no hepatotoxicity in human use.

Another feature of $\alpha$-GalCer that may limit its clinical efficacy is that $\alpha$-GalCer induces iNKT cell anergy. Upon in vitro re-stimulation with $\alpha$-GalCer, splenocytes from $\alpha$-GalCer-injected mice produced only low levels of cytokines and decreased proliferation ability as compared to the first injection. This unresponsive phenomenon of $\alpha$-GalCer treated iNKT cells was thymus independent and can be abrogated by IL-2 [93]. It is well known that in T cells, stimulation of TCRs with weaker ligands induces anergy via up-regulation of the transcription factor egr-2/3, leading to the expression of cbl-b and programmed cell death protein 1 (PD-1) [94]. In line with $\mathrm{T}$ cell anergy, the $\alpha$-GalCer-induced anergy of iNKT cells has been shown to up regulate the expression of cbl-b, PD1 and egr-2/3. Interestingly, $\alpha-G a l C e r$ analogues with phenyl group, which display greater binding avidity and stability to iNKT TCR than $\alpha$-GalCer [60], did not induce the expression of PD-1 and cbl-b, nor anergy upon repeated treatment [64].

The lack of effective elimination of MDSCs by $\alpha$ GalCer is another potential drawback. MDSC is a population of myeloid cells that co-express $C D 11 b^{+}$ and $\mathrm{Gr}^{+}$surface markers and has been shown to suppress anti-CD3/anti-28 induced $\mathrm{T}$ cells proliferation [95], downregulate $\mathrm{CD} 3 \zeta$-chain expression [96], inhibit the CD8 $\mathrm{T}$ cells cytotoxicity, induce $\mathrm{T}$ cells apoptosis [97] and reduce the cytotoxicity of NK cells and activation of NKT cells [98]. Thus, it contributes to hyporesponsiveness of various immune effector cells, resulting in enhanced tumor progression and metastasis $[99,100]$. The suppressive activities of MDSCs are achieved by regulation of L-arginine metabolic pathways. L-arginine is metabolized by arginase to generate urea and L-ornithine or is converted into citrulline and nitric oxide $(\mathrm{NO})$ by inducible nitric oxide synthase (iNOS) [101]. It has been reported that MDSCs produce NO to suppress the immune response in the tumor microenvironment [102]. Repeated injection of $\alpha$-GalCer maintained high level of MDSCs in the spleen and enhanced the expression of PD-1 and PD-L1 as well as arginase 1 and iNOS on MDSCs. Moreover, accumulation of MDSCs was at least in part attributed to up-regulation of G-CSF through IL-33, which was triggered by liver damage [64]. Since treatment of J $18^{-1-}$ mice with $\alpha$-GalCer failed to show accumulation of MDSCs (Fig. 3), in contrast to wild type mice, accumulation of MDSC induced by $\alpha-G a l C e r$ is iNKT celldependent. Thus, strategies to diminish the number or suppressive activity of MDSCs induced by $\alpha$-GalCer might enhance the anti-tumor effect of $\alpha$-GalCer. Recent report that suppression of iNOS by L-NAME, which is an inhibitor for iNOS, enhanced the antitumor effect of $\alpha$-GalCer is consistent with this notion [103]. Another strategy is to modify the structure of $\alpha$ GalCer to reduce the MDSC-promoting activity thereby enhancing its anti-tumor activity. Indeed, phenyl glycolipids did not induce MDSC accumulation in the spleen nor in the tumor microenvironment in contrast to $\alpha$-GalCer. Such structural modification of $\alpha$-GalCer might represent a step in the right direction for the development of more potent NKT-stimulatory glycolipids for cancer therapy [64].

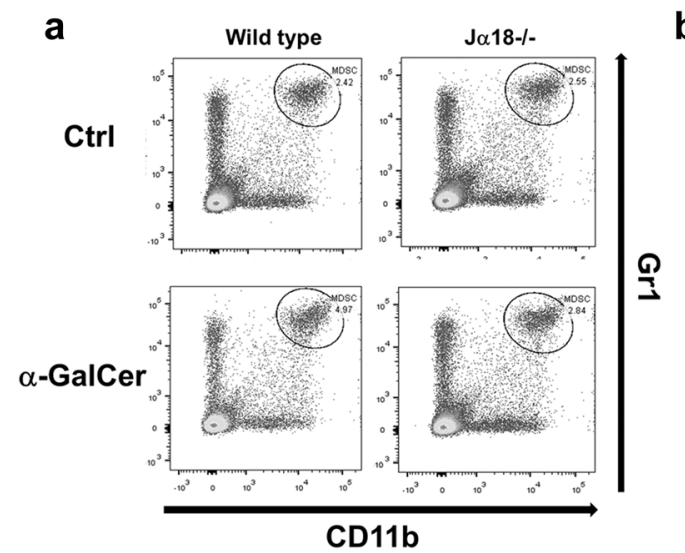

b
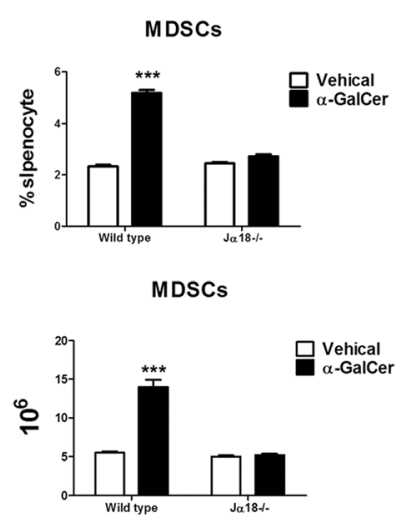

Fig. 3 MDSC accumulation induced by a-GalCer is iNKT cell-dependent. BALB/C and Ja18 ${ }^{-/-}$mice $(n=3$ per group) were intravenously injected with a-GalCer ( $2 \mu \mathrm{g} /$ mouse) or vehicle (1\% DMSO). Three days after administration, MDSCs $\left(C D 11 \mathrm{~b}^{+} \mathrm{Gr} 1^{+}\right)$were determined by FACS analysis. a Representative dot plots of MDSCs in the presence/absence of a-GalCer in wild type and Ja18 ${ }^{-/-}$mice were shown. $\mathbf{b}$ The percentage and total number of MDSCs in splenocyte from each mouse of indicated group are presented and shown as mean \pm SD. ${ }^{* *}, p<0.01$ as compared with vehicle 


\section{Conclusion}

Various modifications on $\alpha$-GalCer have been made, and studies of these $\alpha$-GalCer analogues have shed light on the direction to manipulate the activation of iNKT with desired immune responses. Some of these $\alpha$-GalCer analogues have demonstrated improved efficacy as anticancer agents, vaccine adjuvants and anti-autoimmune agents in animal studies. Therefore, understanding the correlation between structure and activity of $\alpha$-GalCer analogues on the activation of iNKT cells and their molecular mechanism related to immune modulation should facilitate the development of potent immune modulating glycolipids for various diseases. Besides, the route of injection, dose and treatments schedule might influence the therapeutic efficacy of $\alpha$-GalCer. Although the $\alpha$-GalCer did not show good clinical responses in the phase I clinical trials, using low immune suppressive $\alpha$-GalCer analogues and optimized treatment schedule might show better antitumor efficacy in human in the future.

\section{Abbreviations}

CIA: Collagen-induced arthritis; DCs: Dendritic cells; DR5: Death receptor 5; EAE: Experimental autoimmune encephalomyelitis; GVHD: Graft-versus-host

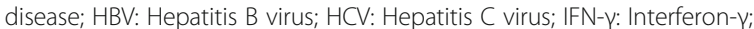
iGB3: isoglobotrihexosylceramide; IL-4: Interleukin-4; iNKT: invariant NKT; iNOS: inducible nitric oxide synthase; MDSCs: Myeloid-derived suppressor cells; MHC: Major histocompatibility complex; NK: Natural killer; NKT: Natural killer T; NO: Nitric oxide; PD-1: Programmed cell death protein 1; TCR: T cell receptor; Treg: Regulatory T; a-GalCer: a-galactosylceramide

\section{Acknowledgements}

We are indebted to Hsiao-Wei Wu for her excellent scientific illustration.

\section{Funding}

This research was supported by grants from the Ministry of Health and Welfare (DOH95-DC-1411), the Ministry of Science and Technology (MOST 105-2320-B-182A-006), the Chang Gung Medical Foundation (OMRPG3C0014 and CMRPG3D1491-3) and Academia Sinica in Taiwan.

\section{Availability of data and materials}

Not applicable.

\section{Authors' contributions}

$J \mathrm{RH}, \mathrm{JTH}$ and ALY have contributed to the organization of the content for this manuscript. JRH and JTH collected relevant information and prepared the draft. ALY drafted and revised the manuscript. All authors read and approved the final manuscript.

\section{Competing interests}

ALY and JTH hold the patent on C34. The authors declare that the patent does not alter the authors' adherence to JBS policies on sharing data and information.

\section{Consent for publication}

Not applicable.

\section{Ethics approval and consent to participate}

Not applicable.

Received: 30 September 2016 Accepted: 20 February 2017 Published online: 23 March 2017

\section{References}

1. Cerundolo V, et al. Harnessing invariant NKT cells in vaccination strategies. Nat Rev Immunol. 2009;9(1):28-38.
2. Godfrey DI, et al. NKT cells: what's in a name? Nat Rev Immunol. 2004;4(3):231-7.

3. Cardell S, et al. CD1-restricted CD4+ T cells in major histocompatibility complex class II-deficient mice. J Exp Med. 1995;182(4):993-1004.

4. Behar SM, et al. Diverse TCRs recognize murine CD1. J Immunol. 1999;162(1):161-7.

5. Bendelac A, Savage PB, Teyton L. The biology of NKT cells. Annu Rev Immunol. 2007;25:297-336

6. Borg NA, et al. CD1d-lipid-antigen recognition by the semi-invariant NKT Tcell receptor. Nature. 2007;448(7149):44-9.

7. Pellicci DG, et al. Differential recognition of CD1d-alpha-galactosyl ceramide by the $\mathrm{V}$ beta 8.2 and $\mathrm{V}$ beta 7 semi-invariant NKT T cell receptors. Immunity. 2009;31(1):47-59.

8. Miyamoto K, Miyake S, Yamamura T. A synthetic glycolipid prevents autoimmune encephalomyelitis by inducing $\mathrm{TH} 2$ bias of natural killer $\mathrm{T}$ cells. Nature. 2001:413(6855):531-4.

9. Schmieg J, et al. Superior protection against malaria and melanoma metastases by a C-glycoside analogue of the natural killer T cell ligand alpha-Galactosylceramide. J Exp Med. 2003;198(11):1631-41.

10. Chang YJ, et al. Potent immune-modulating and anticancer effects of NKT cell stimulatory glycolipids. Proc Natl Acad Sci U S A. 2007;104(25):10299-304.

11. Hung JT, et al. Potent adjuvant effects of novel NKT stimulatory glycolipids on hemagglutinin based DNA vaccine for $\mathrm{H} 5 \mathrm{~N} 1$ influenza virus. Antiviral Res. 2014;107:110-8.

12. Renukaradhya GJ, et al. Type I NKT cells protect (and type II NKT cells suppress) the host's innate antitumor immune response to a B-cell lymphoma. Blood. 2008;111(12):5637-45.

13. Lantz $\mathrm{O}$, Bendelac $\mathrm{A}$. An invariant $\mathrm{T}$ cell receptor alpha chain is used by a unique subset of major histocompatibility complex class I-specific CD4+ and CD4-8- T cells in mice and humans. J Exp Med. 1994;180(3):1097-106.

14. Ohteki T, MacDonald HR. Stringent $V$ beta requirement for the development of NK1.1+ T cell receptor-alpha/beta + cells in mouse liver. J Exp Med. 1996;183(3):1277-82.

15. Arase $\mathrm{H}$, et al. An NK1.1+ CD4+8- single-positive thymocyte subpopulation that expresses a highly skewed T-cell antigen receptor $V$ beta family. Proc Natl Acad Sci U S A. 1992;89(14):6506-10.

16. Ohteki T, MacDonald HR. Major histocompatibility complex class I related molecules control the development of CD4+8- and CD4-8- subsets of natural killer 1.1+ T cell receptor-alpha/beta + cells in the liver of mice. J Exp Med. 1994;180(2):699-704.

17. MacDonald HR. NK1.1+ T cell receptor-alpha/beta + cells: new clues to their origin, specificity, and function. J Exp Med. 1995;182(3):633-8.

18. Bendelac A, et al. Mouse CD1-specific NK1 T cells: development, specificity, and function. Annu Rev Immunol. 1997:15:535-62.

19. Dellabona $\mathrm{P}$, et al. An invariant $\mathrm{V}$ alpha $24-\mathrm{J}$ alpha $\mathrm{Q} N$ beta $11 \mathrm{~T}$ cell receptor is expressed in all individuals by clonally expanded CD4-8- T cells. J Exp Med. 1994;180(3):1171-6.

20. Porcelli $S$, et al. Analysis of T cell antigen receptor (TCR) expression by human peripheral blood CD4-8- alpha/beta T cells demonstrates preferential use of several $\mathrm{V}$ beta genes and an invariant TCR alpha chain. J Exp Med. 1993;178(1):1-16.

21. Liao CM, Zimmer MI, Wang CR. The functions of type I and type II natura killer T cells in inflammatory bowel diseases. Inflamm Bowel Dis. 2013;19(6):1330-8.

22. Brossay $L$, et al. CD1d-mediated recognition of an alpha-galactosylceramide by natural killer T cells is highly conserved through mammalian evolution. J Exp Med. 1998;188(8):1521-8.

23. Kawano T, et al. CD1d-restricted and TCR-mediated activation of valpha14 NKT cells by glycosylceramides. Science. 1997;278(5343):1626-9.

24. Spada FM, Koezuka Y, Porcelli SA. CD1d-restricted recognition of synthetic glycolipid antigens by human natural killer T cells. J Exp Med. 1998;188(8):1529-34

25. Brossay L, et al. Mouse CD1 is mainly expressed on hemopoietic-derived cells. J Immunol. 1997:159(3):1216-24.

26. Koch $M$, et al. The crystal structure of human CD1d with and without alphagalactosylceramide. Nat Immunol. 2005;6(8):819-26.

27. Zeng Z, et al. Crystal structure of mouse CD1: An MHC-like fold with a large hydrophobic binding groove. Science. 1997;277(5324):339-45.

28. Zajonc DM, et al. Structural basis for CD1d presentation of a sulfatide derived from myelin and its implications for autoimmunity. J Exp Med. 2005;202(11):1517-26.

29. Zajonc DM, et al. Structure and function of a potent agonist for the semiinvariant natural killer T cell receptor. Nat Immunol. 2005;6(8):810-8. 
30. Giabbai B, et al. Crystal structure of mouse CD1d bound to the self ligand phosphatidylcholine: a molecular basis for NKT cell activation. J Immunol. 2005;175(2):977-84.

31. Zajonc DM, et al. Structural characterization of mycobacterial phosphatidylinositol mannoside binding to mouse CD1d. J Immunol. 2006;177(7):4577-83.

32. Moody DB, Zajonc DM, Wilson IA. Anatomy of CD1-lipid antigen complexes. Nat Rev Immunol. 2005;5(5):387-99.

33. Matsuda $J$, et al. Tracking the response of natural killer T cells to a glycolipid antigen using CD1d tetramers. J Exp Med. 2000;192(5):741-54

34. Hong $S$, et al. Lipid antigen presentation in the immune system: lessons learned from CD1d knockout mice. Immunol Rev. 1999;169:31-44.

35. Burdin N, et al. Selective ability of mouse CD1 to present glycolipids: alphagalactosylceramide specifically stimulates $\mathrm{V}$ alpha 14+ NK T lymphocytes. J Immunol. 1998;161(7):3271-81.

36. Stetson DB, et al. Constitutive cytokine mRNAs mark natural killer (NK) and NK T cells poised for rapid effector function. J Exp Med. 2003;198(7):1069-76.

37. Carnaud C, et al. Cutting edge: Cross-talk between cells of the innate immune system: NKT cells rapidly activate NK cells. J Immunol. 1999;163(9):4647-50.

38. Fujii $\mathrm{S}$, et al. Activation of natural killer T cells by alpha-galactosylceramide rapidly induces the full maturation of dendritic cells in vivo and thereby acts as an adjuvant for combined CD4 and CD8 T cell immunity to a coadministered protein. J Exp Med. 2003;198(2):267-79.

39. Denkers EY, et al. A role for CD4+ NK1.1+ T lymphocytes as major histocompatibility complex class $\|$ independent helper cells in the generation of CD8+ effector function against intracellular infection. J Exp Med. 1996;184(1):131-9.

40. Apostolou l, et al. Murine natural killer T(NKT) cells [correction of natural killer cells] contribute to the granulomatous reaction caused by mycobacterial cell walls. Proc Natl Acad Sci U S A. 1999;96(9):5141-6.

41. Kakimi K, et al. Natural killer T cell activation inhibits hepatitis B virus replication in vivo. J Exp Med. 2000;192(7):921-30.

42. Rissoan MC, et al. Reciprocal control of T helper cell and dendritic cell differentiation. Science. 1999;283(5405):1183-6.

43. Arrenberg $P$, et al. Oligoclonality and innate-like features in the TCR repertoire of type II NKT cells reactive to a beta-linked self-glycolipid. Proc Natl Acad Sci U S A. 2010;107(24):10984-9.

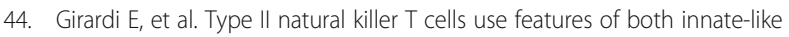
and conventional T cells to recognize sulfatide self antigens. Nat Immunol. 2012;13(9):851-6.

45. Halder RC, et al. Type II NKT cell-mediated anergy induction in type I NKT cells prevents inflammatory liver disease. J Clin Invest. 2007;117(8):2302-12.

46. Oh SJ, et al. Role of type II NKT cells in the suppression of graft-versus-hos disease. Crit Rev Immunol. 2008;28(3):249-67.

47. Zhang $G$, et al. Sulfatide-activated type II NKT cells prevent allergic airway inflammation by inhibiting type I NKT cell function in a mouse model of asthma. Am J Physiol Lung Cell Mol Physiol. 2011;301(6):L975-84.

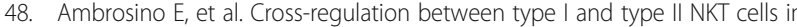
regulating tumor immunity: a new immunoregulatory axis. J Immunol. 2007:179(8):5126-36

49. Chang DH, et al. Inflammation-associated lysophospholipids as ligands for CD1d-restricted T cells in human cancer. Blood. 2008;112(4):1308-16.

50. Hix LM, et al. CD1d-expressing breast cancer cells modulate NKT cellmediated antitumor immunity in a murine model of breast cancer metastasis. PLoS One. 2011;6(6):e20702.

51. Izhak $\mathrm{L}$, et al. Delicate balance among three types of $T$ cells in concurrent regulation of tumor immunity. Cancer Res. 2013;73(5):1514-23.

52. Kobayashi E, et al. KRN7000, a novel immunomodulator, and its antitumor activities. Oncol Res. 1995;7(10-11):529-34.

53. Natori T, Koezuka Y, Higa T. Agelasphins, novel a-galactosylceramides from the marine sponge Agelas mauritianus. Tetrahedron Lett. 1993;34(35):5591-2

54. Morita M, et al. Structure-activity relationship of alpha-galactosylceramides against B16-bearing mice. J Med Chem. 1995;38(12):2176-87.

55. Mizuno $\mathrm{M}$, et al. Synthetic glycolipid $\mathrm{OCH}$ prevents insulitis and diabetes in NOD mice. J Autoimmun. 2004:23(4):293-300.

56. Savage PB, Teyton L, Bendelac A. Glycolipids for natural killer T cells. Chem Soc Rev. 2006:35(9):771-9.

57. Wu D, Fujio M, Wong CH. Glycolipids as immunostimulating agents. Bioorg Med Chem. 2008;16(3):1073-83.

58. McCarthy C, et al. The length of lipids bound to human CD1d molecules modulates the affinity of NKT cell TCR and the threshold of NKT cell activation. J Exp Med. 2007;204(5):1131-44.
59. Oki S, et al. The clinical implication and molecular mechanism of preferential IL-4 production by modified glycolipid-stimulated NKT cells. J Clin Invest. 2004;113(11):1631-40.

60. Wu TN, et al. Avidity of CD1d-ligand-receptor ternary complex contributes to T-helper 1 (Th1) polarization and anticancer efficacy. Proc Natl Acad Sci U S A. 2011;108(42):17275-80.

61. Tashiro T, et al. RCAl-17, 22, 24-26, 29, 31, 34-36, 38-40, and 88, the analogs of KRN7000 with a sulfonamide linkage: their synthesis and bioactivity for mouse natural killer T cells to produce Th2-biased cytokines. Bioorg Med Chem. 2008;16(19):8896-906.

62. Padte NN, et al. A glycolipid adjuvant, 7DW8-5, enhances CD8+ T cell responses induced by an adenovirus-vectored malaria vaccine in non-human primates. PLoS One. 2013:8(10):e78407.

63. Wu TA, et al. Phenyl Glycolipids with Different Glycosyl Groups Exhibit Marked Differences in Murine and Human iNKT Cell Activation. ACS Chem Biol. 2016. in press.

64. Huang JR, et al. alpha-Galactosylceramide but not phenyl-glycolipids induced NKT cell anergy and IL-33-mediated myeloid-derived suppressor cell accumulation via upregulation of egr2/3. J Immunol. 2014;192(4):1972-81.

65. Raju R, et al. Synthesis and evaluation of 3"- and 4"-deoxy and -fluoro analogs of the immunostimulatory glycolipid, KRN7000. Bioorg Med Chem Lett. 2009;19(15):4122-5.

66. Prigozy $\mathrm{Tl}$, et al. Glycolipid antigen processing for presentation by CD1d molecules. Science. 2001;291(5504):664-7.

67. Zhou XT, et al. Synthesis and NKT cell stimulating properties of fluorophoreand biotin-appended 6"-amino-6"-deoxy-galactosylceramides. Org Lett. 2002;4(8):1267-70

68. Ebensen T, et al. A pegylated derivative of alpha-galactosylceramide exhibits improved biological properties. J Immunol. 2007;179(4):2065-73.

69. Aspeslagh S, et al. Galactose-modified iNKT cell agonists stabilized by an induced fit of CD1d prevent tumour metastasis. EMBO J. 2011;30(11):2294-305.

70. Pauwels N, et al. Divergent synthetic approach to 6"-modified alpha-GalCer analogues. Org Biomol Chem. 2011;9(24):8413-21.

71. Hsieh $\mathrm{MH}$, et al. Synthesis and evaluation of acyl-chain- and galactose-6"modified analogues of alpha-GalCer for NKT cell activation. Chembiochem. 2012:13(11):1689-97.

72. Hung J-T, et al. Design and synthesis of galactose-6-OH-modified [small alpha]-galactosyl ceramide analogues with Th2-biased immune responses. RSC Adv. 2014;4(88):47341-56.

73. Aspeslagh S, et al. Enhanced TCR footprint by a novel glycolipid increases NKT-dependent tumor protection. J Immunol. 2013;191(6):2916-25.

74. Park JJ, et al. Synthesis of all stereoisomers of KRN7000, the CD1d-binding NKT cell ligand. Bioorg Med Chem Lett. 2008;18(14):3906-9.

75. Fuhshuku K, et al. RCAI-8, 9, 18, 19, and 49-52, conformationally restricted analogues of KRN7000 with an azetidine or a pyrrolidine ring: Their synthesis and bioactivity for mouse natural killer T cells to produce cytokines. Bioorg Med Chem. 2008:16(2):950-64.

76. Shiozaki $M$, et al. Synthesis and biological activity of ester and ether analogues of alpha-galactosylceramide (KRN7000). Carbohydr Res. 2010;345(12):1663-84

77. Birkholz AM, et al. A Novel Glycolipid Antigen for NKT Cells That Preferentially Induces IFN-gamma Production. J Immunol. 2015;195(3):924-33.

78. Li X, et al. Identification of C-glycoside analogues that display a potent biological activity against murine and human invariant natural killer $T$ cells. Immunology. 2009;127(2):216-25.

79. Giaccone $\mathrm{G}$, et al. A phase I study of the natural killer T-cell ligand alphagalactosylceramide (KRN7000) in patients with solid tumors. Clin Cancer Res. 2002;8(12):3702-9.

80. Crough T, et al. Modulation of human Valpha24(+)Vbeta11(+) NKT cells by age, malignancy and conventional anticancer therapies. Br J Cancer. 2004;91(11):1880-6.

81. Toura I, et al. Cutting edge: inhibition of experimental tumor metastasis by dendritic cells pulsed with alpha-galactosylceramide. J Immunol. 1999;163(5):2387-91.

82. van der Vliet HJ, et al. Potent expansion of human natural killer $\mathrm{T}$ cells using alpha-galactosylceramide (KRN7000)-loaded monocyte-derived dendritic cells, cultured in the presence of IL-7 and IL-15. J Immunol Methods. 2001:247(1-2):61-72.

83. Fujii S, et al. Prolonged IFN-gamma-producing NKT response induced with alpha-galactosylceramide-loaded DCs. Nat Immunol. 2002;3(9):867-74.

84. Nieda M, et al. Therapeutic activation of Valpha24 + Vbeta11+ NKT cells in human subjects results in highly coordinated secondary activation of acquired and innate immunity. Blood. 2004;103(2):383-9. 
85. Chang DH, et al. Sustained expansion of NKT cells and antigen-specific T cells after injection of alpha-galactosyl-ceramide loaded mature dendritic cells in cancer patients. J Exp Med. 2005;201 (9):1503-17.

86. Uchida T, et al. Phase I study of alpha-galactosylceramide-pulsed antigen presenting cells administration to the nasal submucosa in unresectable or recurrent head and neck cancer. Cancer Immunol Immunother. 2008;57(3):337-45.

87. Kunii $\mathrm{N}$, et al. Combination therapy of in vitro-expanded natural killer T cells and alpha-galactosylceramide-pulsed antigen-presenting cells in patients with recurrent head and neck carcinoma. Cancer Sci. 2009;100(6):1092-8.

88. Nicol AJ, Tazbirkova A, Nieda M. Comparison of clinical and immunological effects of intravenous and intradermal administration of alpha-galactosylceramide (KRN7000)-pulsed dendritic cells. Clin Cancer Res. 2011;17(15):5140-51.

89. Veldt BJ, et al. Randomized placebo controlled phase I/II trial of alphagalactosylceramide for the treatment of chronic hepatitis C. J Hepatol. 2007:47(3):356-65

90. Woltman AM, et al. Alpha-galactosylceramide in chronic hepatitis B infection: results from a randomized placebo-controlled Phase I/I trial. Antivir Ther. 2009;14(6):809-18.

91. Osman Y, et al. Activation of hepatic NKT cells and subsequent liver injury following administration of alpha-galactosylceramide. Eur J Immunol. 2000:30(7):1919-28.

92. Sullivan BA, Kronenberg M. Activation or anergy: NKT cells are stunned by alpha-galactosylceramide. J Clin Invest. 2005;115(9):2328-9.

93. Parekh W, et al. Glycolipid antigen induces long-term natural killer $T$ cell anergy in mice. J Clin Invest. 2005;115(9):2572-83.

94. Zheng Y, Zha Y, Gajewski TF. Molecular regulation of T-cell anergy. EMBO Rep. 2008;9(1):50-5.

95. Dugast AS, et al. Myeloid-derived suppressor cells accumulate in kidney allograft tolerance and specifically suppress effector T cell expansion. J Immunol. 2008;180(12):7898-906.

96. Hanson EM, et al. Myeloid-derived suppressor cells down-regulate L-selectin expression on CD4+ and CD8+ T cells. J Immunol. 2009:183(2):937-44.

97. Moline-Velazquez V, et al. Myeloid-derived suppressor cells limit the inflammation by promoting T lymphocyte apoptosis in the spinal cord of a murine model of multiple sclerosis. Brain Pathol. 2011;21(6):678-91.

98. Li H, et al. Cancer-expanded myeloid-derived suppressor cells induce anergy of NK cells through membrane-bound TGF-beta 1.J Immunol. 2009;182(1):240-9.

99. Bunt SK, et al. Inflammation induces myeloid-derived suppressor cells that facilitate tumor progression. J Immunol. 2006;176(1):284-90.

100. Sinha P, Clements VK, Ostrand-Rosenberg S. Reduction of myeloid-derived suppressor cells and induction of M1 macrophages facilitate the rejection of established metastatic disease. J Immunol. 2005;174(2):636-45.

101. Rodriguez PC, Ochoa AC. Arginine regulation by myeloid derived suppressor cells and tolerance in cancer: mechanisms and therapeutic perspectives. Immunol Rev. 2008;222:180-91.

102. Ochoa AC, et al. Arginase, prostaglandins, and myeloid-derived suppressor cells in renal cell carcinoma. Clin Cancer Res. 2007:13(2 Pt 2):721s-6s.

103. Ito H, Ando T, Seishima M. Inhibition of iNOS activity enhances the antitumor effects of alpha-galactosylceramide in established murine cancer model. Oncotarget. 2015;6(39):41863-74.

\section{Submit your next manuscript to BioMed Central and we will help you at every step:}

- We accept pre-submission inquiries

- Our selector tool helps you to find the most relevant journal

- We provide round the clock customer support

- Convenient online submission

- Thorough peer review

- Inclusion in PubMed and all major indexing services

- Maximum visibility for your research

Submit your manuscript at www.biomedcentral.com/submit

) Biomed Central 